\title{
Improving Efficacy in Group Projects with Teamwork Agreements
}

\section{Dr. Jack Bringardner, New York University}

Jack Bringardner is an Assistant Professor in the First-Year Engineering Program at NYU Tandon School of Engineering. He studied civil engineering and received his B.S. from the Ohio State University and his M.S and Ph.D. at the University of Texas at Austin. His primary focus is developing curriculum and pedagogical techniques for engineering education, particularly in the Introduction to Engineering and Design course at NYU. He has a background in Transportation Engineering and is affiliated with the NYU Civil and Urban Engineering department.

\section{Dr. Christopher Leslie, New York University}

Christopher Leslie is a Lecturer of Science, Technology and Media Studies at the New York University Tandon School of Engineering in Brooklyn, New York, and he is codirector of the Science and Technology Studies program there. Dr. Leslie's research considers the cultural formations that surround technology, science, and media in the 19th- and 20th-century United States. He is the head writing consultant for the Introduction to Engineering and Design course, and also teaches courses in Science and Technology Studies such as the international history of the Internet, the history of science and race, and science fiction.

\section{Prof. Gunter W. Georgi, New York University}

Gunter W. Georgi, a registered Professional Engineer, is an Industry Professor at the New York University Tandon School of Engineering in Brooklyn, New York. Prof. Georgi is the course director for the Introduction to Engineering and Design course. He received his B.S. from Cooper Union and his M.S. and professional M.E. degrees from Columbia University. He has worked many years in the aerospace industry in design, analysis, and management functions. His most challenging task was the responsibility for the Thermal Mission Analysis of the Lunar Module from Project Apollo.

\section{Alyssa Marie D'Apice, New York University}

Alyssa D'Apice is a fourth year undergraduate student pursuing a Bachelor of Science in Chemical and Bio-molecular engineering at the New York University Tandon School of Engineering in Brooklyn, New York. She is one of four head teaching assistants for the Introduction to Engineering and Design course where she manages over 100 student workers, making sure that the course moves seamlessly. While on campus, Alyssa has participated in varsity basketball, volleyball, and softball during her first two years and recently was part of a summer research program where she studied the effects of carbon dioxide and calcium on the viscosity of mucus to help cystic fibrosis patients. 


\title{
Improving Efficacy in Group Projects with Teamwork Agreements
}

\begin{abstract}
This evidence-based practice paper evaluates the effect of a teamwork agreement on efficacy in group-based projects at the NYU Tandon School of Engineering. Teamwork is an essential part of engineering education and the profession, but some students have a negative attitude towards group-based academic assignments. The paper addresses the typical topic of interest for firstyear engineering programs related to advising first-year students on group work. One method for improving student attitudes towards group work, other than in-class team-based projects, is to provide a seminar on teamwork skills. Despite this training, some teams still fail to connect the concepts with practice. As a means of actively engaging students in the teamwork training, several sections of a first-year multidisciplinary engineering design course were required to create their own teamwork agreement with the assistance of the course instructor. The aim of the agreement was to connect the skills discussed in training and the application of these skills to the team-based course project. This agreement was then submitted to the instructor for use in handling teamwork problems during the semester, and students were encouraged to use the recitation instructional team to resolve any problems with teamwork if they occurred. This method was inspired by a common practice used by many engineering team-based capstone courses at the senior level. Teamwork agreements act as a contract between team members to fulfill their established duties. They take the form of a brief document outlining the team members' responsibilities and expectations related to teamwork, not the course project. Control sections were used to evaluate if there was a difference between students who use the teamwork agreement and those who did not. Asking questions directly related to the teamwork agreement would result in stated preference data. Instead, asking revealed preference questions on attitudes towards teamwork allowed for an analysis of how the students benefited from the teamwork agreement assignment. Once the control study was completed, a before-after analysis was used to identify statistically significant differences for the treatment sections. A pre-class survey and post-class survey will indicate if the teamwork agreement had a uniformly positive impact. Most survey questions have Likert scale answers to clearly define the responses and enable statistical analysis. Although all students showed an improvement in their teamwork efficacy, the students who participated in the teamwork agreement showed significantly greater improvements.
\end{abstract}

\section{Introduction}

Teamwork has long been a part of engineering practice, and for many years it has been codified in the ABET 2000 guidelines in Criterion 3 letter d: "ability to function on multidisciplinary teams." Current industry demands not only that individuals can participate in group projects, but also that they can work comfortably with professionals from other disciplinary backgrounds. This increased demand is reflected in the proposed revision to the ABET teamwork guideline in Criterion 3, now labeled number 7: one outcome of an engineering education should be that students have gained the ability to function on teams, but also that these teams should "establish goals, plan tasks, meet deadlines, and analyze risk and uncertainty.” In previous work at the 
NYU Tandon School of Engineering (previously known as Polytechnic University) in Brooklyn, New York, it was found that many students thought that they had experience working on teams, but it was suspected that many of those team experiences were working on a project simultaneously. Engineering programs will have to do more to demonstrate their effort for genuine teamwork outcomes, rather than simply relying on group projects, especially with respect to the greater specificity of Criterion 3.7.

Although engineering schools stress teamwork in a variety of ways, more can be done in this regard. One way to inculcate a positive attitude toward teamwork among first-year students is by giving it a prominent place in the curriculum of our first-year introductory course. This effort is inspired by the University of Michigan's Educational Theatre Company's "Off Course” skit. ${ }^{1}$ Devoting one of the course lectures in an introduction to engineering course to a teachingassistant led demonstration of bad and good team member qualities can provide a role model for students. This course's version of this effort has led to qualitatively positive results. ${ }^{2}$ The situations the skit dramatizes run the gamut of causes of teamwork difficulties, from microaggressions to sick family members, with the message that teamwork does not often happen naturally. Instead, team members need to start from the premise that something might go wrong with teamwork and build in safeguards to make sure that obstacles do not derail the team. Students are encouraged to reach out to their teammates, as well as their teaching assistants and recitation instructors, to avoid unfavorable outcomes. The added task of the group construction of agreements was expected to cement this learning and provide an even more favorable improvement in team outcomes.

The introduction to engineering course addressed in this paper is required by most majors in the school of engineering, and the course is designed to provide a foundation in the soft skills students will need in future engineering courses (such as giving presentations, following lab instructions, using software, as well as working on teams). All students in the class meet once a week for lecture, which is where this course's version of the educational theater took place. The course also requires weekly interdisciplinary laboratory experiments and recitations for presentations in sections of up to 18 students. In addition, an independent design project that is developed by teams is required. Students rank their top choices of various design projects and then are placed into teams during the third week of class. Although the conventional wisdom on teamwork is that larger teams that students organize for less than a semester's duration might be more successful classroom experiences, the focus of this study was to determine whether or not this course's approach to teamwork would also be effective. The course's instructional team holds that the course requirement that groups of two or three students complete semester-long design projects is more reflective of industry practice: one does not get to choose one's teammates when working for a corporation. Furthermore, one might fear that asking students to form their own teams would lead to enhancing the social stratification that is felt by students of traditionally underrepresented groups in engineering, such as women and students of color. Leaving the design of teams to the instructor ensures that, when possible, each team can have a mix of demographic backgrounds as well as a blend of majors. Thus, these projects are a great opportunity to start students thinking professionally about making teams function well. 
As in past years, this course has continued its presentation about teamwork in the third week of class, at the point when students are being formed into teams. This year, an additional teamwork exercise was added by piloting the use of a teamwork agreement that is crafted by the students themselves in their recitation sections. It was expected that students who used the teamwork agreement would be more confident in their ability to work in a team than the control group who did not. Of those groups that did encounter difficulty, it was believed that the groups who complete the teamwork agreement will have tools to resolve the conflicts and their experience will be better. It was anticipated that there would be an improvement in all students' attitudes toward teamwork after the class compared to before teamwork training and practice, but that there will be better results in the groups who complete the teamwork agreement. It was the goal of this teamwork project to improve students' adjustment to college-level engineering curriculum and offer them necessary interpersonal skills.

\section{Literature Review}

Teamwork in engineering education has been scrutinized from many different perspectives. Most commonly research has focused on how to improve team interactions. For instance, some courses manage teams by providing pre-defined roles for members and pre-selecting the team members based on personality profiles. ${ }^{3}$ Others focus on how team experiences influence student satisfaction in the course. Some have discussed how to address slackers on a team in an educational setting, such as removing students who do not contribute to the team effort. ${ }^{4}$ Recent investigations have looked at how teamwork improves retention throughout undergraduate education. However, now, a focus has shifted from educational exercises to improving soft skills, or skills needed for long-term professional development.

Many studies on teamwork performance and attitudes have identified the need for professional skills as a primary motivator for emphasizing teamwork in the classroom. It has been shown that teamwork assignments can increase self-efficacy for most students. ${ }^{5}$ Improving student efficacy is a critical component to success in education as well as success in industry. A number of methods for improving student self-confidence in succeeding have been tested. Two common techniques that have been implemented in first-year engineering courses are a teamwork training session and the use of teamwork agreements. Teamwork training, seminars, or orientations attempt to provide students without teamwork experience the knowledge necessary to practice team skills. Teamwork agreements, charters, or contracts are used to provide the guidelines that would exist in the workplace.

Several teamwork training exercises have been examined as potential models for other educators. IDEALS focuses on aspects of teamwork, team member expectations, roles, responsibilities, feedback, and review. ${ }^{6}$ A combination of in-class exercises and homework assignments allow students to reflect on engineering teamwork. The CARE model focuses on communication, adaptation, relation, and education. ${ }^{7}$ These models attempt to add to the curriculum rather than be a foundation for hands on learning. 
Some less comprehensive approaches to teamwork training have been developed to encourage hands on curricular strategies. Providing roles for team members and requiring a rotation through these roles relieves some of the uncertainty in team experiences. ${ }^{8}$ It has been shown that direct interaction between the team and the instructor can improve the success of teams. ${ }^{3}$ Other programs have produced teamwork skits that demonstrate to students the potential problems and solutions in teamwork. ${ }^{1,2}$ The success of these smaller strategies suggest that hands on experience is particularly important in teamwork skills development. They also allow for a more approachable teamwork training system, as they do not require several hours of course time.

Teamwork training can then be reinforced through the use of a teamwork agreement. Team problems are often associated with one member not contributing or cooperating with the rest of the team. Rather than waiting until halfway through a course project, there is the potential to address the issues, or at least have students consider them, before they become a problem. This positive regulation of teams has been shown to be more effective than negative, or reactionary, regulation. ${ }^{9}$ Teamwork agreements are used by both the IDEALS framework and the CARE model. ${ }^{6,70}$ Some aspects that both of these programs focus on include expectations, roles, tasks, accountability, and communication. Each of these methods require students to address these issues in a teamwork contract before teamwork begins. This gives students a chance to understand why teams succeed and fail before they develop their teamwork behavior. ${ }^{11}$

Many aspects of behavior have been examined for the usefulness in teamwork agreements from a variety of studies. In particular, this paper aims to address attitudes towards teamwork that will influence the ability to succeed in a professional setting. These attitudes focus on previous team experience, team experience in the course, leadership of other team members, enjoyment of teamwork, the importance of teamwork to the engineering profession, methods for collaboration, and equal contributions from team members. ${ }^{1,3,8,12}$ These concepts, related to engineering, were incorporated into a survey used for this paper to determine attitudes of students in a first-year engineering design course.

Common methods of assessment for engineering education team experience include open-ended survey questions with text analytics and Likert scale survey questions. ${ }^{3,8}$ The CARE model and the IDEALS learning systems have specific surveys catered to their lessons. It is more common to develop a survey particular to the curriculum being tested. A first step of investigating open ended questions usually leads to a follow up survey, which asks for specific responses related to the most important topics identified in the open-ended questions. ${ }^{3,7,8}$ It has also been shown that a more sophisticated study can produce a before and after analysis based on Likert scale surveys administered in the beginning and end of the course.,12

\section{Methods}

In the fall semester, one-third of the sections of the first-year Introduction to Engineering and Design were chosen to complete teamwork agreements (referred to here as treatment sections) and the rest proceeded without any intervention (control sections). This experience was used as a 
trial run for the teamwork agreements, providing us an opportunity to test our data-gathering method and also allowing our faculty and teaching assistants' time to understand the agreement (attached as an Appendix). Those students who were in the sections with teamwork agreements were also told that they should bring any teamwork conflicts they have to the recitation instructor, who would devote time to resolving the issue and making suggestions on how the team could operate more effectively. Students were asked if they wanted to share their agreements for this study, and those who did submitted them to a teaching assistant who helped protect student anonymity. It was decided that data collection using Qualtrics, an online response management tool, would be more expedient than the original plan of using clickers.

An application for human subjects research was made to the Institutional Review Board (IRB). Although the survey was designed so that no identifying personal information was collected, the study still involved interaction with a vulnerable population. Students were receiving grades in the class, yet their participation in the study had to be voluntary. It was easy enough for a student to decline to participate in a survey, but the teamwork agreement was a different matter. This was handled by asking students to volunteer to submit their agreements to a third party, who then stripped the comments of any identifiable material. This way, the authors did not know which students chose to participate and which did not. This teamwork agreement was then changed appropriately to gain consent and converted into a document that students could complete electronically.

After gaining approval of the IRB, results of this experience were studied quantitatively in the spring semester. Approximately 110 students registered for the spring semester. These were broken into 9 sections for undergraduates, some visiting high school students also take the course, but in special sections. Six sections were designated as treatment sections. A survey using Qualtrics was distributed to the class immediately before the teamwork skit. As seen in Figure 1, survey questions addressed several aspects of student attitudes towards teamwork, including previous experience on teams and the degree to which the teams were self-directed. Students indicated which section of the course they were registered for, which allowed us to distinguish responses from teamwork and control sections. At the end of the semester, a similar follow-up survey was conducted; this survey asked the same Likert questions but had different preliminary questions - documented in Figure 2. Analysis of statistical distributions of the responses determined areas lacking in the training. It identified potential alterations to the teamwork training to address aspects of teamwork that students still view negatively. The number of responses for the pre-class survey was 51 and the number of responses for post-class survey was 66. 
Preliminary questions:

1. Consent statement. Students who give consent to participate may continue to following questions.

2. What is your recitation/lab section?

3. Have you ever worked on a team project in high school STEM (science, technology, engineering, and math) classes, clubs or summer programs? Answers: Never; once or twice; 3-5 times; more than 5 times.

4. Assignments on my team were usually performed ... Answers: Individually (each member completed assignments separately); together; individually, then combined together; completed by one or two members who contributed the most

5. On past teams, what do you do when teams start to experience problems? Answers: Take over the project and do all the work; complete only your part, hoping there are no consequences; stop working and blame team members; talk to teacher or advisor; call a team meeting and resolve issues.

The remaining questions were evaluated using a Likert scale (strongly disagree/disagree/neutral/agree/strongly agree):

6. In my previous experience, my team was responsible for determining the goals and outcome of the project.

7. On average, I have had a lot of responsibility on my team(s).

8. My ideas were respected and used by my team(s).

9. The workload was evenly distributed across all group members.

10. I know what to do to make sure all my teammates do their part to make a project a success.

11. I can accomplish more as a team rather than individually.

12. Teamwork is important to working as a professional engineer.

13. I like teamwork.

Figure 1: Pre-Class Survey Questions 
Preliminary questions:

3. What is your reaction to teamwork in this course? (open response question)

4. Assignments on my [redacted course name] team were performed ... Answers: Individually (each member completed assignments separately); together; individually, then combined together; completed by one or two members who contributed the most.

5. This semester, if teamwork problems developed, what did you do? Answers: Take over the project and do all the work; complete only your part, hoping there are no consequences; stop working and blame team members; talk to teacher, teaching assistant, or writing consultant; call a team meeting and resolve issues.

The following questions were evaluated using a Likert scale (strongly disagree/disagree/neutral/agree/strongly agree):

6. In my EG team experience, my role remained constant throughout the entire project.

7. This semester, I have had a lot of responsibility on my team(s).

8. My ideas were respected and used by my [redacted course name] team.

9. The [redacted project name] workload was evenly distributed across all group members.

Questions 10-13 of the pre-experience survey were repeated here.

Figure 2: Post-Class Questions

\section{Results}

The results of this experimental study are Likert scale responses to a survey conducted before and after a team project. The typical process for developing a Likert scale survey is 1) generating the topics of interest, 2) evaluating the reliability of the topics and scale used to respond to the survey, 3) investigating the data, and 4) analyzing for statistically significant differences. Once a set of topics has been established it is important to calculate Cronbach's Alpha in order to determine the validity of the scaled responses. ${ }^{13}$ After the survey has been validated, hypothesized differences should be evaluated using the Wilcoxon Rank-Sum test for equal distributions. ${ }^{14}$ T-tests are often used for Likert scale questions, but the assumptions of a normal distribution is weak for Likert scale responses. The Wilcoxon Rank-Sum test is robust to violations of normality. A summary report of significant differences and their magnitudes should be presented.

The Cronbach's Alpha for this survey was 0.780 , which is considered acceptable to good for the reliability of the scales used for the questions asked. This means that the responses to the Likert scale questions are capable of addressing the underlying principles associated with teamwork. In other words, the student responses are consistent and not random.

Table 1 provides an overview of the data analysis performed for this research. The results will be presented using histograms, frequency distribution charts, statistical comparison tabulations, and summary of open-ended responses. 
Table 1: Overview of the Analysis of Survey Question Responses

\begin{tabular}{|cc|}
\hline Analysis & Figure/Table \\
\hline $\begin{array}{c}\text { Histogram of Non-Likert Scale Questions in Pre-Class } \\
\text { and Post-Class Surveys }\end{array}$ & Figure 3, 4, 5, 6, 7 \\
$\begin{array}{c}\text { Frequency Distribution of Likert Scale Responses in Pre-Class } \\
\text { and Post-Class Survey }\end{array}$ & Figure 8, 9 \\
$\begin{array}{c}\text { Tabulation of Statistical Comparison Test of Pre-Class Survey } \\
\text { for Treatment vs. Control }\end{array}$ & Table 2 \\
$\begin{array}{c}\text { Summary of Open-Ended Responses } \\
\text { Tabulation of Statistical Comparison Test of Post-Class Survey } \\
\text { for Treatment vs. Control }\end{array}$ & Table 3 \\
Tabulation of Statistical Comparison Test for Pre-Class and \\
$\begin{array}{c}\text { Post-Class Survey of Control Group } 4 \\
\text { Tabulation of Statistical Comparison Test for Pre-Class and } \\
\text { Post-Class Survey of Treatment Group }\end{array}$ \\
Teamwork Agreement Statements Summary & Table 5 \\
\hline
\end{tabular}

As seen in Figure 3, it appears that many students have either had a single team experience or have had several prior to their undergraduate degree. This could be a result of the disparity between technological high schools and traditional high schools, where technical high schools have many opportunities for students to work on teams. Some students have not had any technical team project experience, which is important to address in training and the teamwork agreement.

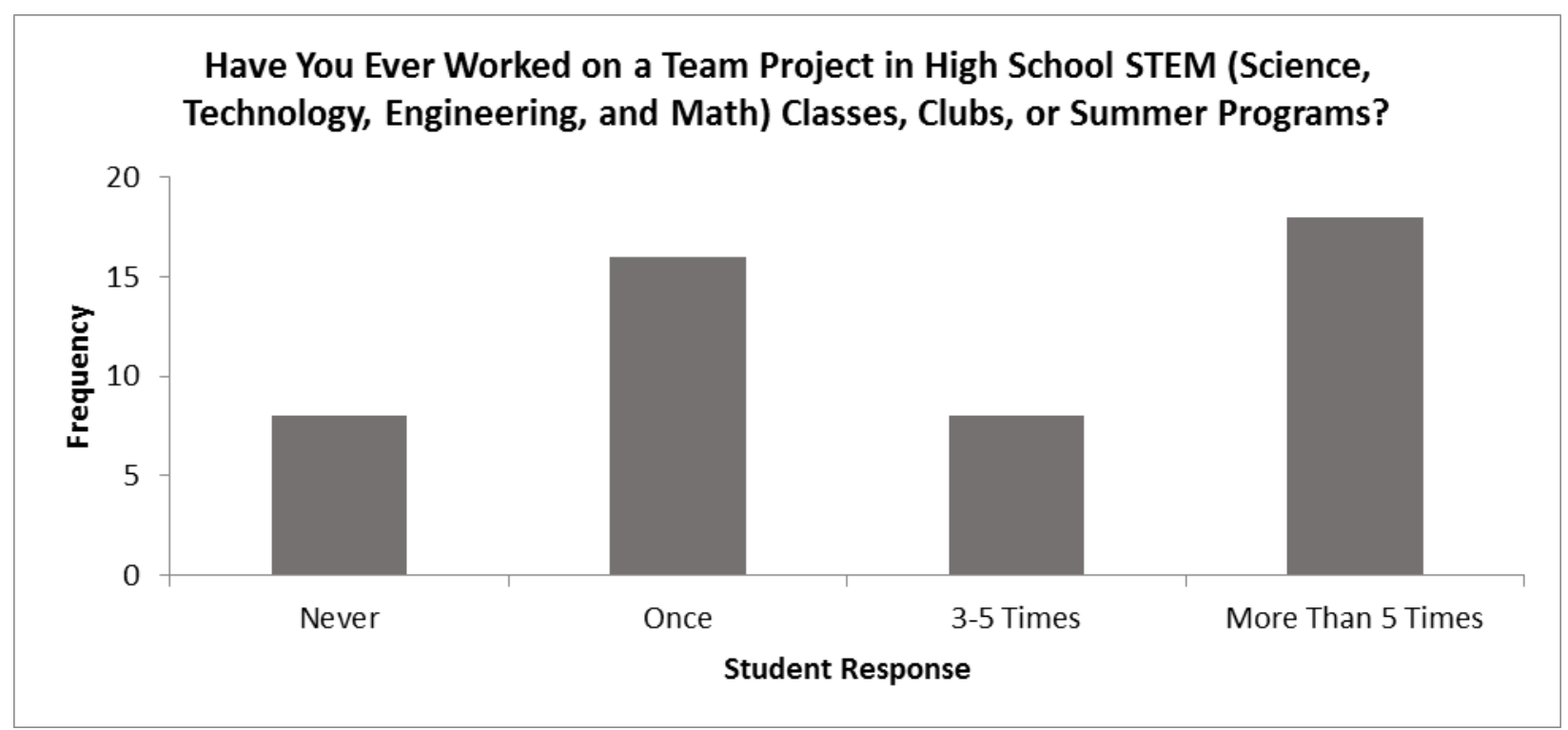

Figure 3: Student Pre-Class Responses on Previous STEM Team Project Experience 
It is more common to work on team projects together or separately, then combining sections, which is a positive response. However, many students either had individual assignments or the assignments were completed by the most dedicated members on the team according to Figure 4 . As can be seen in Figure 5, students in the NYU Tandon course were much less likely to state that they completed the project independently.

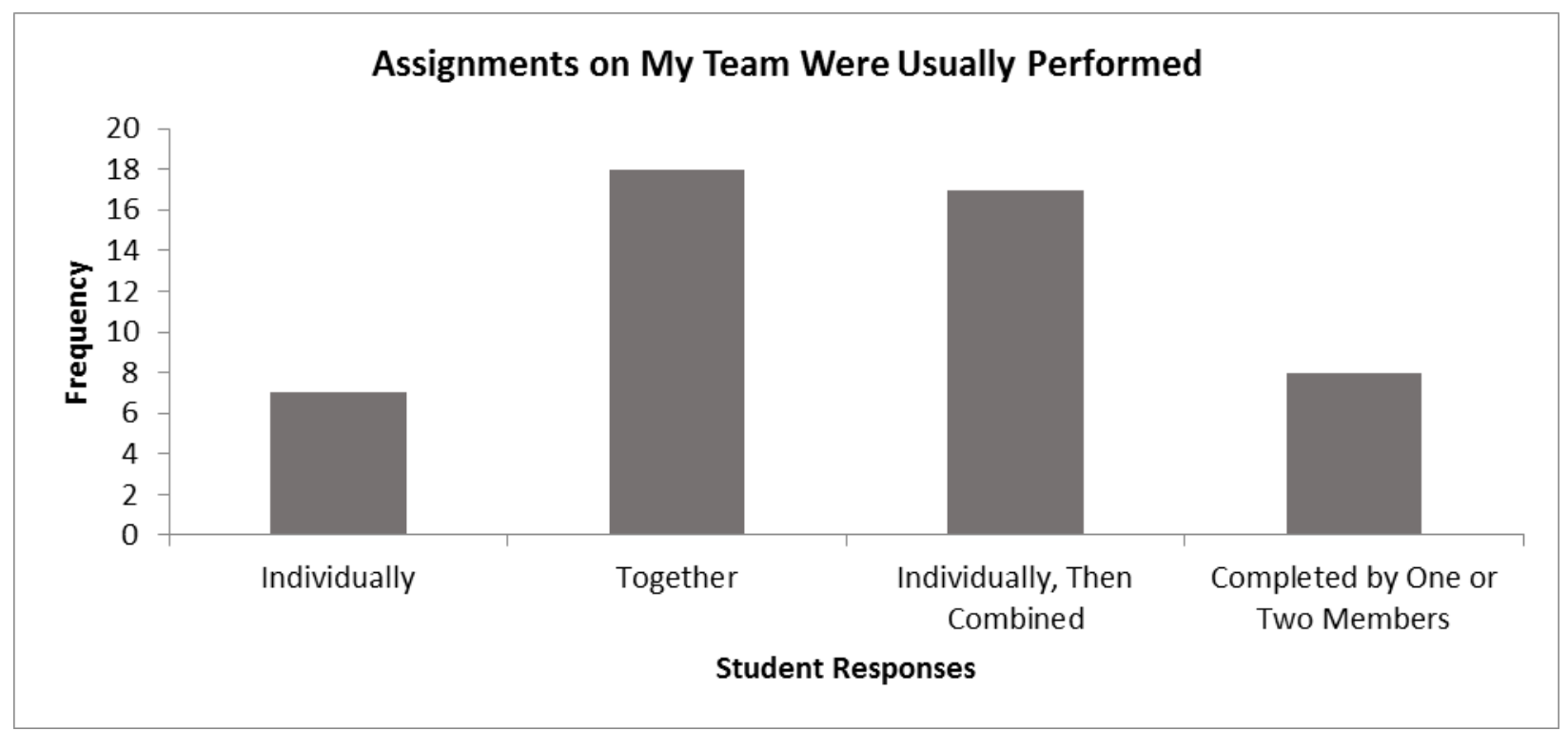

Figure 4: Student Pre-Class Responses on How Team Projects were Completed

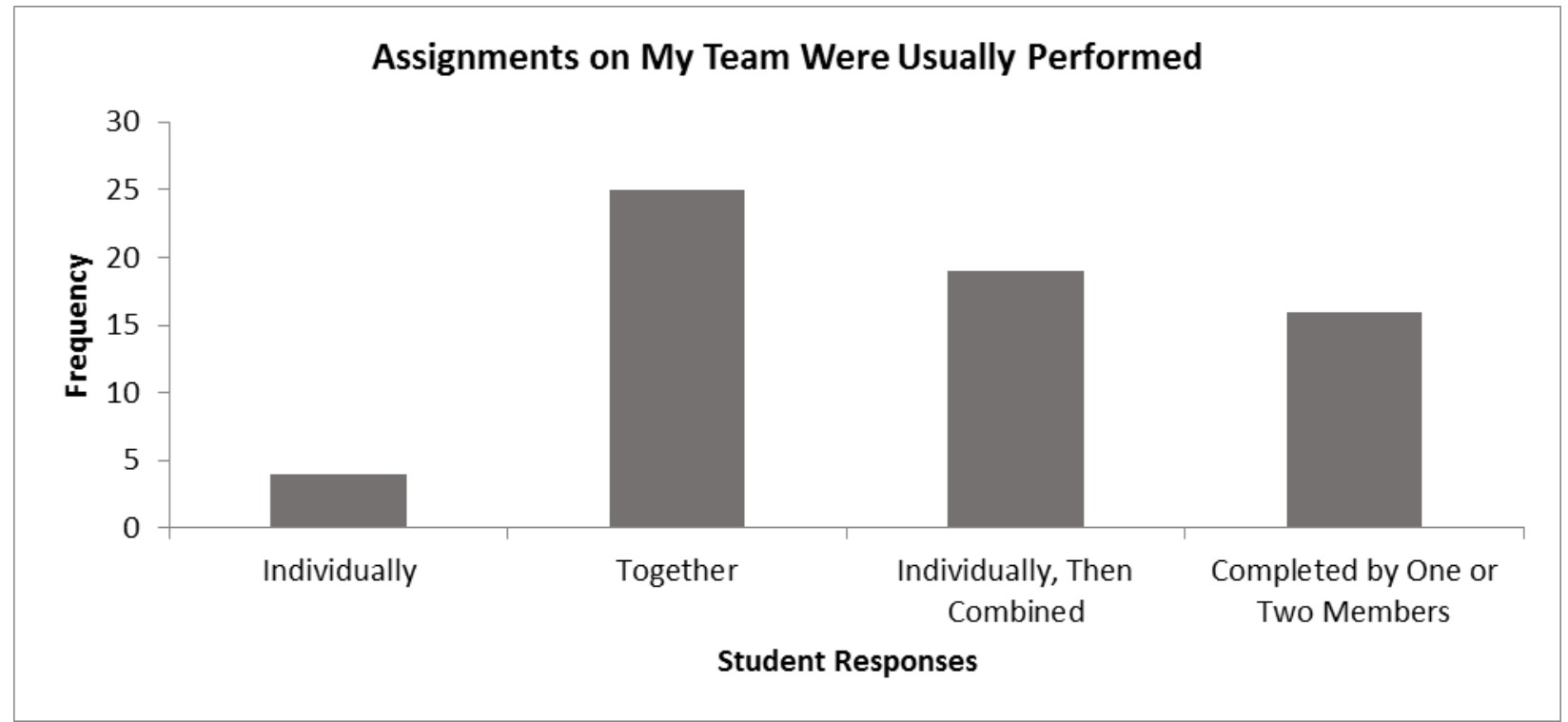

Figure 5: Post-Class Student Responses in on How Team Projects were Completed 
Most students call a team meeting to resolve issues, but hopefully the teamwork agreement will make this a more common strategy. It is important to reduce the number of students who take over the project as seen in Figure 6. A common complaint about teamwork in the classroom is that students feel as if they have to do all of the work themselves when the team breaks down.

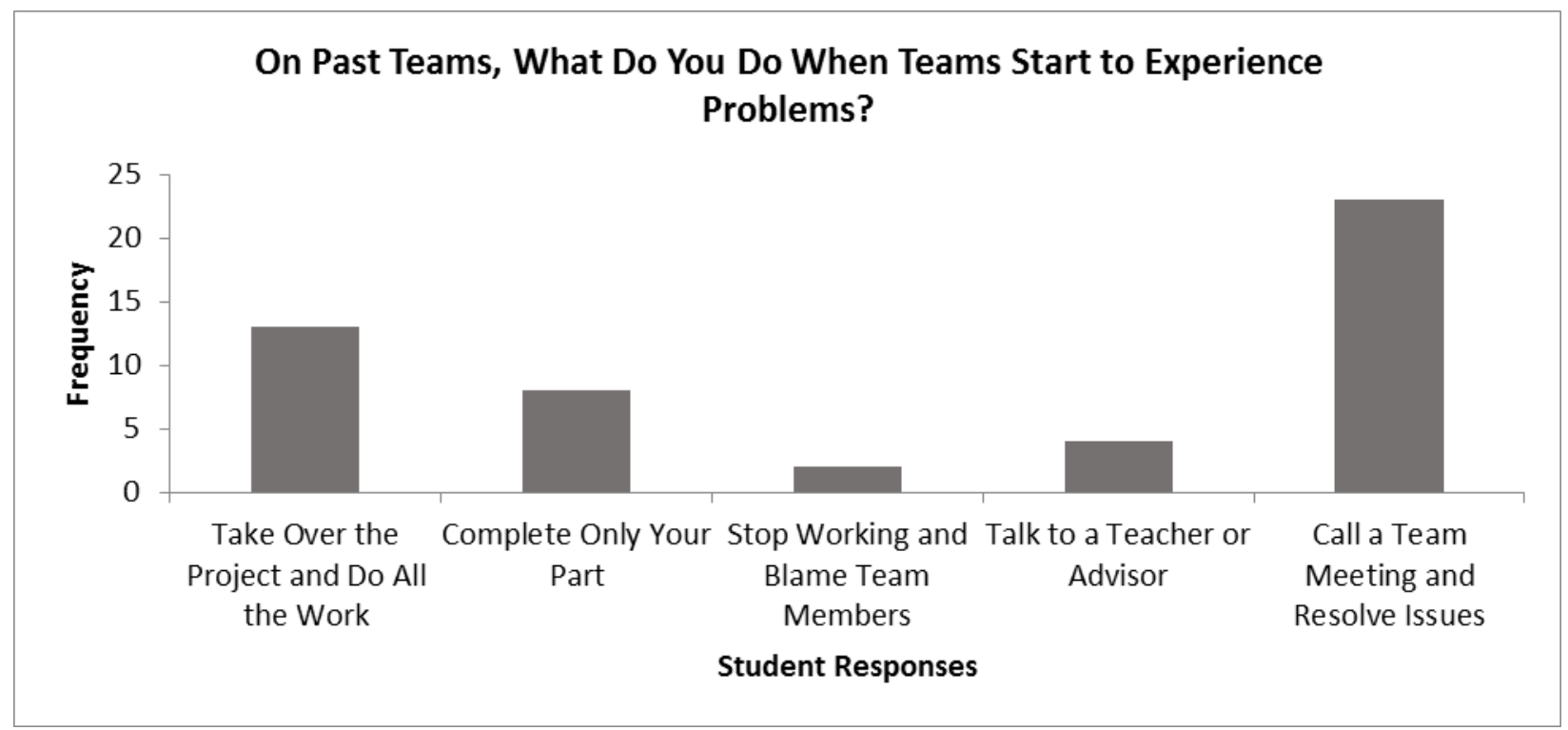

Figure 6: Student Pre-Class Responses on How They Resolved Team Problems

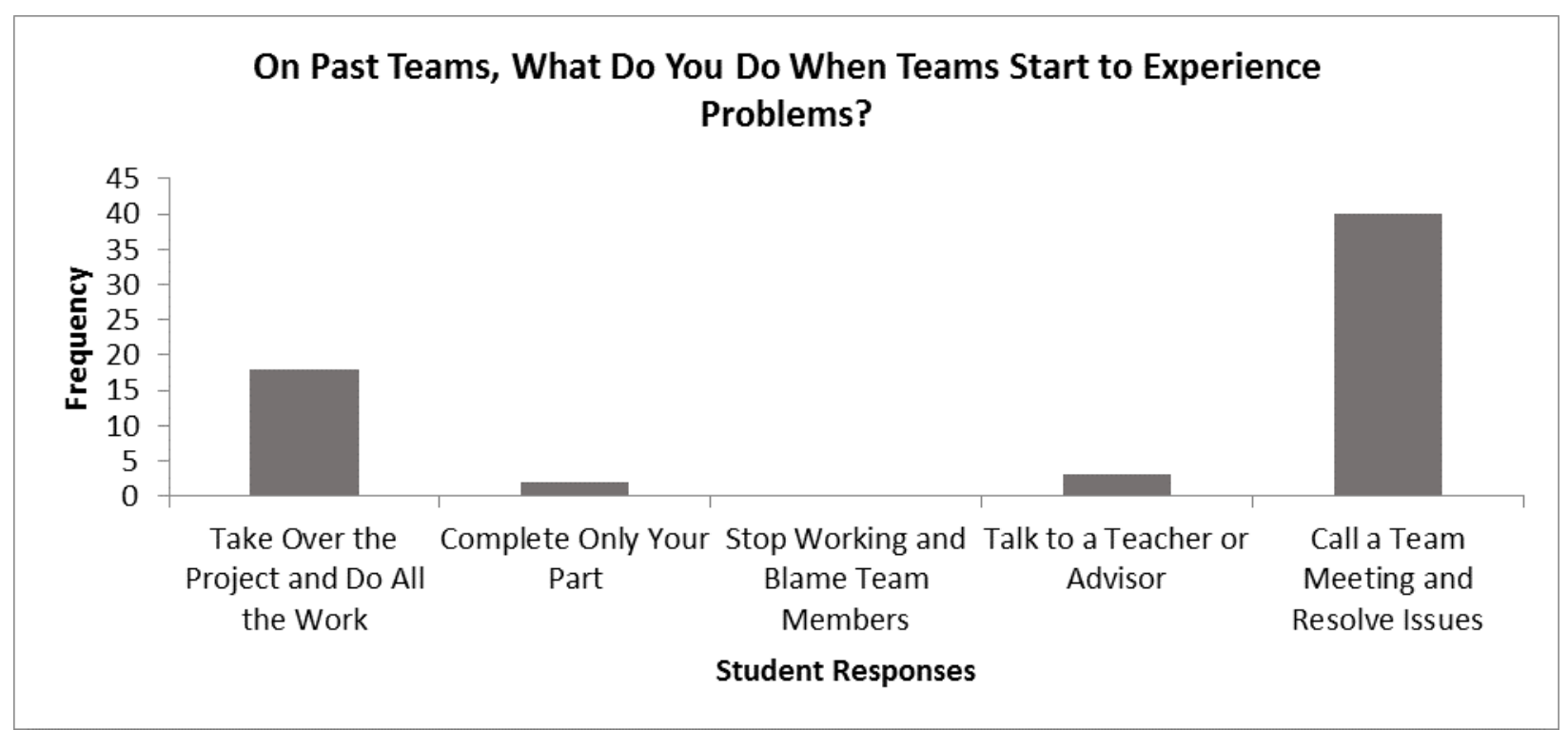

Figure 7: Student Post-Class Responses How They Resolved Team Problems

As can be seen in the comparison of Figures 6 and 7, the students did not necessarily achieve an improvement in taking over the project. However, as seen in the Figure 7, students were much more likely to call a team meeting rather than complete only their part or blame other team members. 


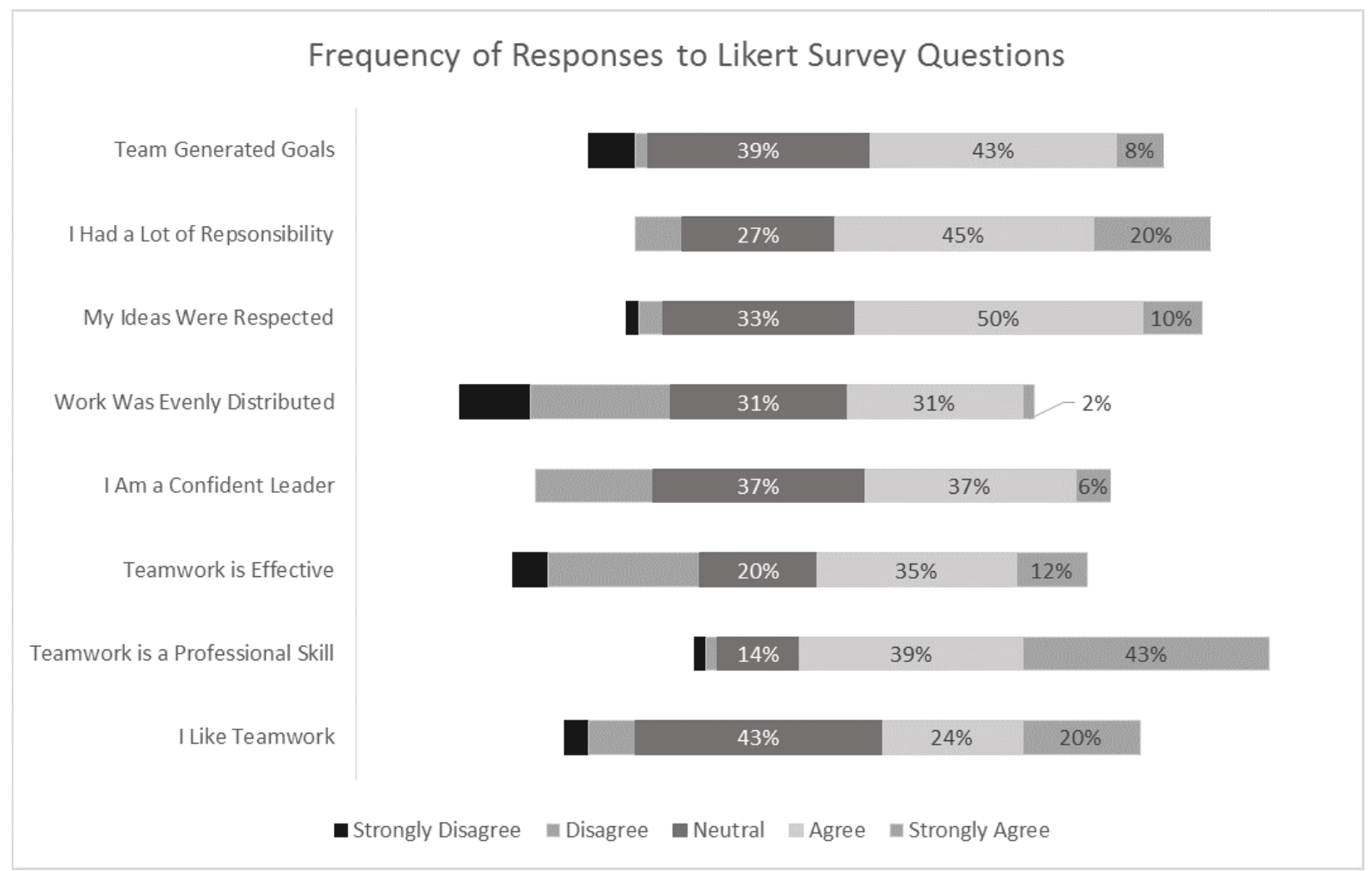

Figure 8: Frequency Distribution of Percent Pre-Class Likert Responses to Teamwork Issues

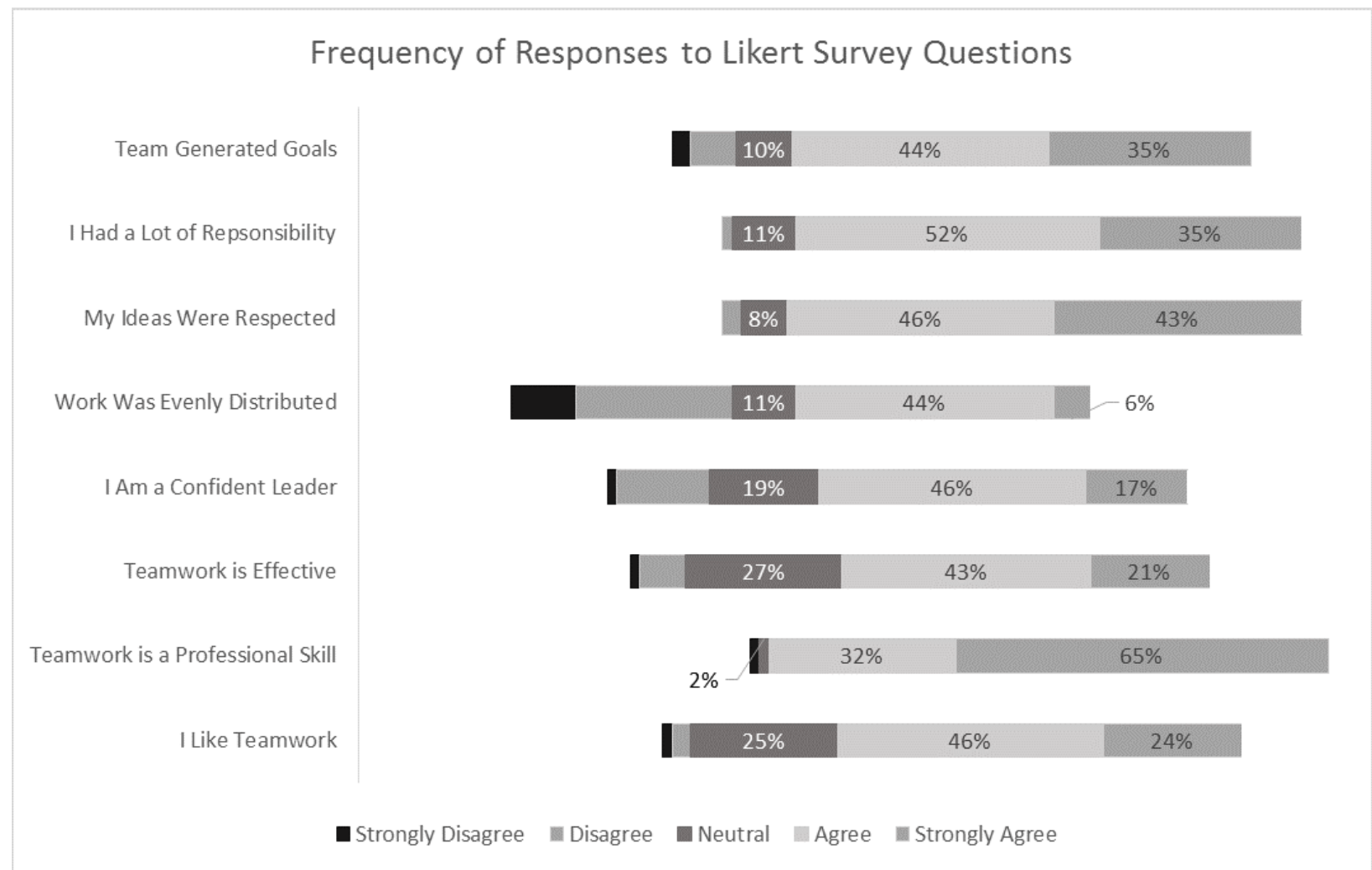

Figure 9: Frequency Distribution of Percent Post-Class Likert Responses to Teamwork Issues 
Figure 8 provides an overall frequency distribution of responses for each Likert question in the pre-class survey. The bar chart is centered on the neutral responses. The post-experience result is shown in Figure 9. As was expected, an overwhelming number of students indicated that they had already participated in teams. As seen in Figure 8, however, only 51\% indicated that their teamwork experience would reflect what was demanded in ABET Criterion 3.7: that the group set goals and managed the work process. With respect to team interaction, Figure 8 shows that a majority of students felt they had a lot of responsibility and that their ideas were respected. However, it is noted that only a third of students felt that the work was evenly distributed to team members. This would seem to indicate that the students in the class took on more than what they perceived was their fair share of the work. There were mixed reactions for student confidence on their leadership abilities, which indicates that a significant number of students feel they lack efficacy in creating a positive team experience.

Although the responses to some of the pre-class questions indicate that students were confident about their teamwork skills and have had positive experiences on teams, the answers to the question on whether teams are more efficient than individuals were revealing, where only $49 \%$ of students believed they could perform better on a team than they could alone and also in the final question, where $44 \%$ said they enjoyed teamwork. $82 \%$ of students agree that teamwork is an essential skill for the engineering profession.

In Figure 9, the rightward shift in the bars demonstrate a major shift in the positive direction for student responses related to each topic on teamwork issues. Most obvious were the questions related to team-generated goals, responsibility, and the general appreciation of teamwork.

Table 2: Statistical Comparison of Treatment and Control in Pre-Class Survey

\begin{tabular}{|ccccc|}
\hline Teamwork Issue & $\begin{array}{c}\text { Treatment* } \\
\text { Pre-Class } \\
\text { Likert Average }\end{array}$ & $\begin{array}{c}\text { Control* } \\
\text { Pre-Class } \\
\text { Likert Average }\end{array}$ & $\begin{array}{c}\text { Absolute } \\
\text { Difference }\end{array}$ & $\begin{array}{c}\text { P Value Rank } \\
\text { Sum }\end{array}$ \\
\hline Ieam Generated Goals & 3.395 & 3.455 & 0.060 & 0.959 \\
My a Lot of Responsibility & 3.658 & 4.182 & 0.524 & 0.053 \\
Work Was Wvenly Distributed & $\mathbf{3 . 4 8 6}$ & $\mathbf{4 . 0 9 1}$ & $\mathbf{0 . 6 0 4}$ & $\mathbf{0 . 0 1 8 ^ { * * }}$ \\
I Am a Confident Leader & 3.184 & 3.091 & 0.301 & 0.384 \\
Teamwork is Effective & 3.237 & 3.636 & 0.452 & 0.097 \\
Teamwork is a Professional Skill & 4.105 & 3.091 & 0.146 & 0.747 \\
I Like Teamwork & 3.421 & 4.455 & 0.349 & 0.387 \\
\hline
\end{tabular}

*Treatment means they used a teamwork agreement; control means no teamwork agreement

** Indicates that the difference is statistically significant at the 95\% confidence level

The information that is seen in Figure 8 is an overview of student responses. However, due to the potential for sample errors, no statistically significant conclusions can be made. Table 2 provides a summary of average responses for each Likert question and a statistical comparison of the two groups. The treatment group are sections that required the teamwork agreement and the control 
group are sections that did not complete the teamwork agreement assignment. Values that were found to be statistically significant indicate that before the experience there were already differences between treatment and control group. The results in Table 2 indicate that the only difference between the treatment and control group in the pre-class survey were related to ideas being respected in teams. This means that, on average, the sections without the teamwork agreement felt like their ideas were more respected than the treatment sections. This difference can be examined to see if it remains significant and decreases in the post-survey.

The open-ended question in the post-survey offered insight into student thinking about teamwork. Table 3 highlights several of the common themes in student responses regarding teamwork in the first-year engineering course.

Table 3: Summary of Open-Ended Question

\section{Typical Responses to What Is Your Reaction to Teamwork in This Course?}

I like the idea of teamwork because you get to build upon each other's ideas and learn new things.

I think the teamwork required in this course is very important in helping us develop a better sense of whats to come.

It is a nice way to learn to collaborate with other students who often think differently. Teamwork is necessary in any engineering field and i think that this class helps students experience the wide range of personalities that one may face when working in a group if people.

Teamwork is a fundamental skill all engineers have to learn, and I think EG 1003 teaches it sufficiently and provides opportunities for teamwork to floruish

I learned that I don't like working with people.

It was hard to divide up work because some cared more about this course than others.

Table 4: Statistical Comparison of Treatment vs. Control in Post-Class Survey

\begin{tabular}{|ccccc|}
\hline Teamwork Issue & $\begin{array}{c}\text { Treatment* } \\
\text { Post-Survey } \\
\text { Likert Average }\end{array}$ & $\begin{array}{c}\text { Control* } \\
\text { Post-Survey } \\
\text { Likert Average }\end{array}$ & $\begin{array}{c}\text { Absolute } \\
\text { Difference }\end{array}$ & $\begin{array}{c}\text { P Value Rank } \\
\text { Sum }\end{array}$ \\
\hline Ieam Generated Goals & 3.980 & 4.077 & 0.097 & 1.000 \\
My a Lot of Responsibility & 4.200 & 4.231 & 0.031 & 0.978 \\
Work Was Wvenly Distributed & 4.320 & 4.154 & 0.166 & 0.410 \\
I Am a Confident Leader & 3.020 & 3.308 & 0.288 & 0.328 \\
Teamwork is Effective & 3.660 & 3.846 & 0.286 & 0.358 \\
Teamwork is a Professional Skill & 4.531 & 4.000 & 0.340 & 0.205 \\
I Like Teamwork & 3.900 & 4.769 & 0.239 & 0.199 \\
\hline
\end{tabular}

*Treatment means they used a teamwork agreement; control means no teamwork agreement

Table 4 shows there were no significant difference between the teamwork and control group in the post-class survey. 
Table 5: Statistical Comparison of Control between Pre-Class and Post-Class

\begin{tabular}{|ccccc|}
\hline Teamwork Issue & $\begin{array}{c}\text { Control* Pre- } \\
\text { Class Likert } \\
\text { Average }\end{array}$ & $\begin{array}{c}\text { Control* Post- } \\
\text { Class Likert } \\
\text { Average }\end{array}$ & $\begin{array}{c}\text { Absolute } \\
\text { Difference }\end{array}$ & $\begin{array}{c}\text { P Value Rank } \\
\text { Sum }\end{array}$ \\
\hline Team Generated Goals & 3.455 & 4.077 & 0.622 & 0.097 \\
I Had a Lot of Responsibility & 4.182 & 4.231 & 0.049 & 0.779 \\
Work Was Evenly Distributed & 4.091 & 4.154 & 0.063 & 0.788 \\
I Am a Confident Leader & 3.091 & 3.308 & 0.217 & 0.533 \\
Teamwork is Effective & 3.091 & 3.846 & 0.210 & 0.613 \\
Teamwork is a Professional Skill & 4.455 & 4.000 & 0.909 & 0.072 \\
I Like Teamwork & 3.727 & 4.769 & 0.315 & 0.129 \\
\hline
\end{tabular}

*Treatment means they used a teamwork agreement; control means no teamwork agreement

Table 5 shows that there were no statistically significant differences between the beginning and end of the class for the sections that did not use the teamwork agreement.

Table 6: Statistical Comparison of Treatment between Pre-Class and Post-Class

\begin{tabular}{|ccccc|}
\hline Teamwork Issue & $\begin{array}{c}\text { Treatment* } \\
\text { Pre-Class Likert } \\
\text { Average }\end{array}$ & $\begin{array}{c}\text { Treatment* } \\
\text { Post-Class Likert } \\
\text { Average }\end{array}$ & $\begin{array}{c}\text { Absolute } \\
\text { Difference }\end{array}$ & $\begin{array}{c}\text { P Value Rank } \\
\text { Sum }\end{array}$ \\
\hline Team Generated Goals & $\mathbf{3 . 3 9 5}$ & $\mathbf{3 . 9 8 0}$ & $\mathbf{0 . 5 8 5}$ & $\mathbf{0 . 0 0 4 ^ { * * }}$ \\
I Had a Lot of Responsibility & $\mathbf{3 . 6 5 8}$ & $\mathbf{4 . 2 0 0}$ & $\mathbf{0 . 5 4 2}$ & $\mathbf{0 . 0 0 5 * *}$ \\
My Ideas Were Respected & $\mathbf{3 . 4 8 6}$ & $\mathbf{4 . 3 2 0}$ & $\mathbf{0 . 8 3 4}$ & $\mathbf{0 . 0 0 0 ^ { * * }}$ \\
Work Was Evenly Distributed & 2.789 & 3.020 & 0.231 & 0.436 \\
I Am a Confident Leader & 3.184 & 3.560 & 0.376 & 0.088 \\
Teamwork is Effective & 3.237 & 3.660 & 0.423 & 0.124 \\
Teamwork is a Professional Skill & 4.105 & 4.531 & 0.425 & 0.068 \\
I Like Teamwork & $\mathbf{3 . 4 2 1}$ & $\mathbf{3 . 9 0 0}$ & $\mathbf{0 . 4 7 9}$ & $\mathbf{0 . 0 3 3 ^ { * * }}$ \\
\hline
\end{tabular}

*Treatment means they used a teamwork agreement; control means no teamwork agreement ** Indicates that the difference is statistically significant at the $95 \%$ confidence level

Table 6 reveals the areas that the teamwork agreement was most successful in changing the attitudes of students before and after the class. The course project is designed so that the students generate their own goals, which differs from projects they have worked on before attending college. Similarly, students felt they had much more responsibility in the course, than in previous projects. The statistical comparison test indicates that the teamwork agreement helped improve students' sense of respect on their teams. Additionally, students tended to like teamwork more after completing the course project and the teamwork agreement.

In the treatment sections, several groups volunteered to submit their teamwork agreements. Their responses were indicative of the problems that undergraduate students think they will encounter. Table 7 summarizes the issues that our teaching assistants have identified from the teamwork agreements. 
Table 7: Teamwork Issues Addressed by Students in Teamwork Agreements

\begin{tabular}{|c|c|}
\hline Teamwork Agreement Section & Summary of Common Responses \\
\hline Communication & $\begin{array}{l}\text { email, texting, Google Drive, Facebook, Facebook } \\
\text { Messenger, or Skype }\end{array}$ \\
\hline Meetings & $\begin{array}{l}\text { meetings once a week, biweekly, or specified the } \\
\text { number of hours they would spend in the meetings }\end{array}$ \\
\hline Differences of Opinion & majority vote \\
\hline Responsibilities & based on strengths and skills \\
\hline Workload & distributed fairly and equally \\
\hline
\end{tabular}

Students were asked if they would like to share their teamwork agreement and, as stated earlier in the methods section, a teaching assistant helped protect the identities of those students who agreed to participate. The students were provided with a basic outline and explanation of what is expected in a teamwork agreement (as seen in the Appendix and Table 7), which included five different categories: communication, meetings, differences of opinion, responsibilities, and workload.

Teams were also asked what would happen if a member does not show up to a meeting. Many stated that the team meeting would continue and other team member would be updated using one of the communication methods. One team's response was characteristic of many of the other responses:

"If a team member doesn't show for a meeting, he is responsible for contacting other members for update information and finishing his portion of work as soon as possible or contributing in another way."

The responses indicate that the students understand they are still responsible for their work regardless of whether they are able to attend the meeting, further allowing the students to realize their roles within the team. When their roles conflict with one another, a few teams also added that they would listen to their group member's ideas and try to convince the other members of their idea. One representative team's answer can be seen below:

“Tied votes on decisions will be resolved by reconsidering every member's opinions and choosing the option that works best for the entire team. If there are disagreements during problem solving, each member should state their reasons for disagreeing and offer possible solutions to the issue. “

The teamwork agreement appeared to make the teams think about how they would solve issues and communicate to make sure the projects get done well and on time. By making the students think about how to solve problems and hold other members responsible, they are already prepared on how to approach the situation, even if they are not exactly aware on how to solve the problem. Figure 10 and 11 show a team solving a problem with their project and working together to develop a solution - their robot needed to climb a hill. 


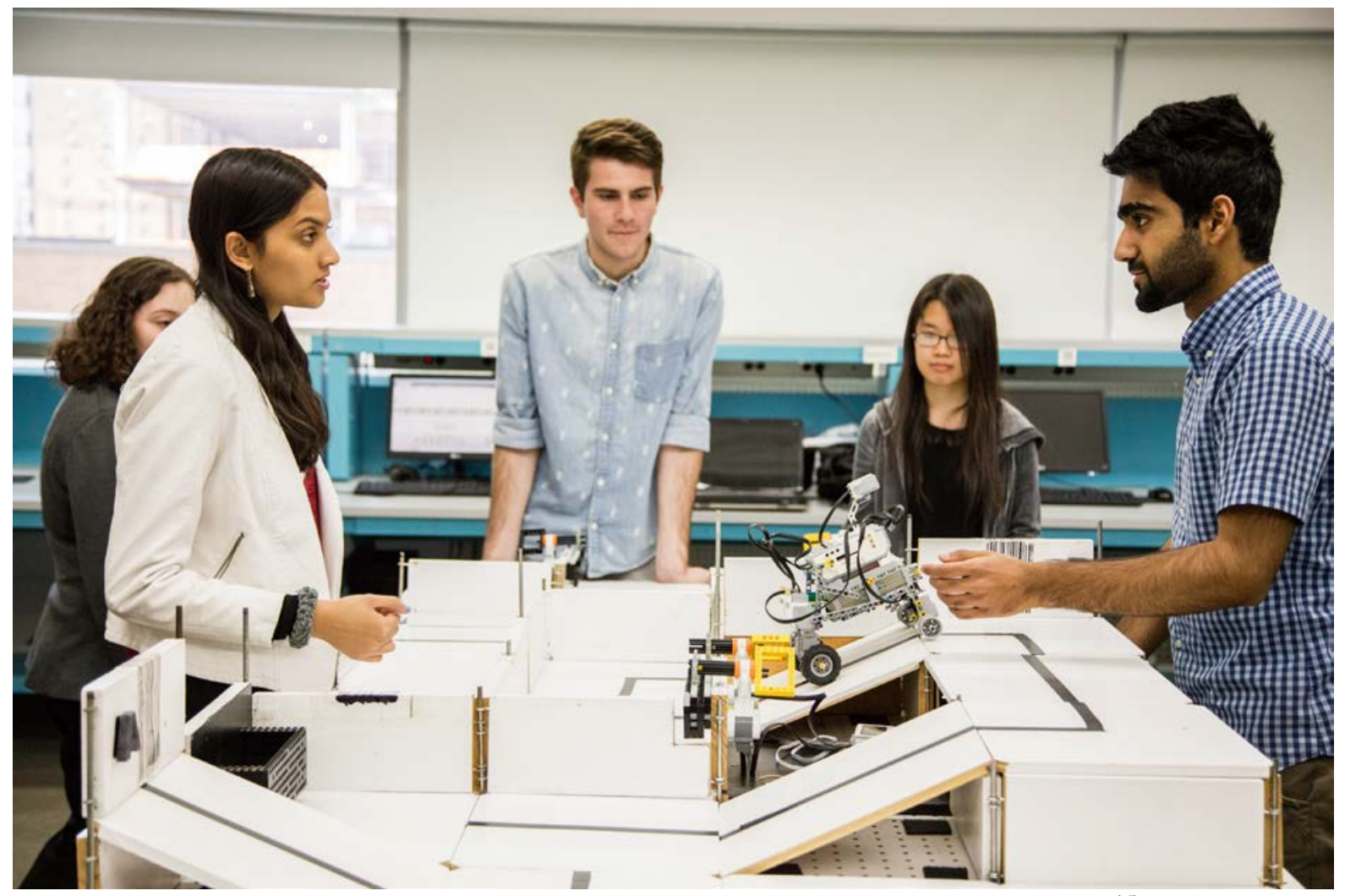

Figure 10: Team Members Identify an Obstacle That They Need to Overcome ${ }^{15}$

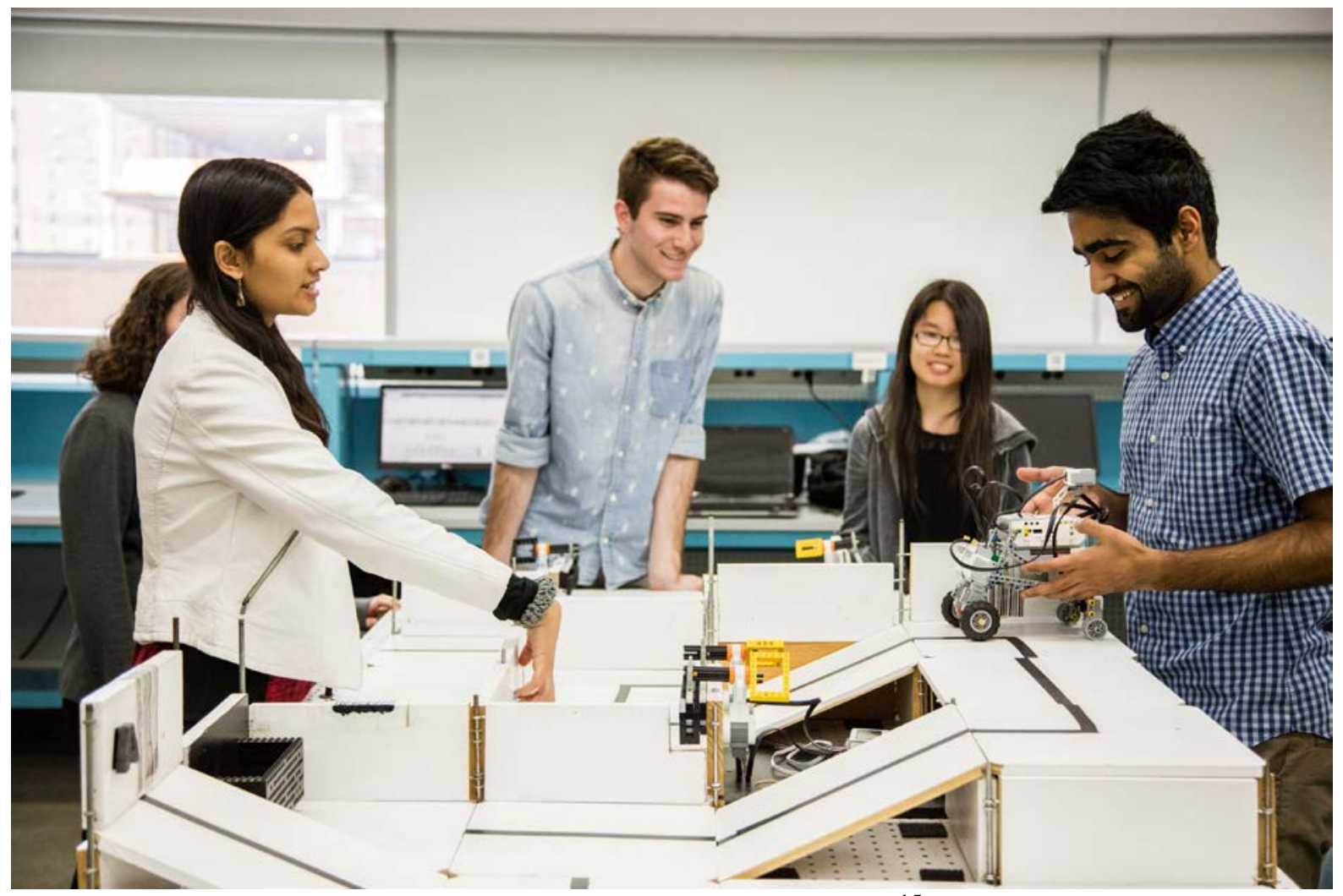

Figure 11: Team Members Design a Solution to Their Problem ${ }^{15}$ 


\section{Conclusions}

As was anticipated, explicitly addressing teamwork in this first-year course led to an improvement in students' efficacy. In particular, the teamwork agreement, or teamwork contract, was most effective in the areas of student teams generating their own ideas, students' sense of responsibility, students' respect for each other ideas, and an overall appreciation of teamwork. Some modifications should be made to the teamwork agreement to better address fairness or workload, leadership skills, effectiveness of team projects, and professional skills associated with teamwork.

It cannot be expected that an educational intervention will present marked changes in student behavior. The assumption that addressing teamwork in a variety of modalities throughout the course seems well founded. Nevertheless, there was a statistically significant difference in the groups that used the teamwork agreement over those who did not.

It is clear that this approach is effective in changing attitudes toward teamwork. It could be valuable to compare the changes of teamwork efficacy in this course to that of first-year students who are not required to take this course at the Tandon School of Engineering. This broader study, using a control group of students who are not in the Introduction to Engineering course, would help to demonstrate the extent to which changes are due to the course rather than the firstyear experience of college.

\section{References}

1. Kendall-Brown, M., \& Finelli, C. (2009, June), Using An Interactive Theater Sketch To Improve Students' Perceptions About And Ability To Function On Diverse Teams Paper presented at 2009 Annual Conference \& Exposition, Austin, Texas. https://peer.asee.org/4967

2. Leslie, C., \& Georgi, G. W., \& D'Apice, A. M. (2015). A Student-led Approach to Promoting Teamwork in an Introductory Engineering Presentation. Paper presented at 2015 ASEE Annual Conference and Exposition, Seattle, Washington. 10.18260/p.23453.

3. Oakley, B., Hanna, D. M., Kuzmyn, Z., \& Felder, R. M. (2007). Best practices involving teamwork in the classroom: Results from a survey of 6435 engineering student respondents. Education, IEEE Transactions on, 50(3), 266-272.

4. Knight, D. W., Carlson, L. E., \& Sullivan, J. (2007, June). Improving engineering student retention through hands-on, team based, first-year design projects. In Proceedings of the International Conference on Research in Engineering Education.

5. Hutchison, M. A., Follman, D. K., Sumpter, M., \& Bodner, G. M. (2006). Factors influencing the selfefficacy beliefs of first-year engineering students. JOURNAL OF ENGINEERING EDUCATIONWASHINGTON-, 95(1), 39.

6. Davis, D. C., \& Ulseth, R. R. (2013, June), Building Student Capacity for High Performance Teamwork. Paper presented at 2013 ASEE Annual Conference, Atlanta, Georgia. https://peer.asee.org/19274. 
7. Larson, N. L., \& Hoffart, G., \& O'Neill, T., \& Eggermont, M., \& Rosehart, W. D., \& Brennan, B. (2015, June), Team CARE Model: Assessing Team Dynamics in First-year Engineering Student Teams. Paper presented at 2015 ASEE Annual Conference and Exposition, Seattle, Washington. 10.18260/p.24832.

8. Everett, J. W., \& Morgan, J. K., \& Mallouk, K. E. (2015, June), Pre-defined Roles and Team Performance for First-year Students. Paper presented at 2015 ASEE Annual Conference and Exposition, Seattle, Washington. 10.18260/p.24577.

9. González-Fernández, M. J., Sáiz-Manzanares, M. C., Alaoui, F. E., Aguilar, F., Meneses, J., \& Montero, E. (2013). Introduction of team self-regulation for teamwork promotion. A case study in energy engineering topics. Journal of Technology and Science Education, 3(3), 139-147.

10. Integrated Design Engineering Assessment and Learning System (IDEALS). Accessed January 2016. https://ideals.tidee.org/

11. Gatchell, D., Hirsch, P., Goodman, A., Anderson, J., Carr, S., \& Ankenman, B. (2013). Facilitating Teamwork Instruction in a First-Year Engineering Design Program: a Question of Balance. In Proceedings of the 5th First Year Engineering Experience Conference. Pittsburgh, Pennsylvania.

12. Tolliver, D., \& Hines, L., \& Parsons, J. R. (2006, June), Engineering Students' Perceptions of Attitude Changes in Teamwork. Paper presented at 2006 Annual Conference \& Exposition, Chicago, Illinois. https://peer.asee.org/541.

13. Gliem, J. A., \& Gliem, R. R. (2003). Calculating, interpreting, and reporting Cronbach’s alpha reliability coefficient for Likert-type scales. Midwest Research-to-Practice Conference in Adult, Continuing, and Community Education.

14. Meyers, K. L., Bucks, G. W., Harper, K. A. and Goodrich, V. E. (2015), Multi-Institutional Evaluation of Engineering Discipline Selection Paper presented at 2015 ASEE Annual Conference and Exposition, Seattle, Washington. 10.18260/p.24512

15. Stockbridge, Jeffrey. (2016) Photograph. Jeffrey Stockbridge Studio, Philadelphia, PA. 


\section{EG 1003 Teamwork Agreement}

\section{Assigned in 4th Recitation (Lab 3 Presentations) Due in 5th Recitation (Milestone 1 Presentations)}

Your semester-long design project team is required to draft a contract, or teamwork agreement, that lays out the expectations of each member and consequences for those who do not contribute. If you experience any problems with your teammates during the semester, you are encouraged to reach out to your recitation professor, $\mathrm{TA}$, or writing consultant to have a teamwork consultation. This agreement will be referenced in that meeting.

A teamwork agreement:

- Details the responsibilities of each member of the project.

- Focuses on the process of working as a team, not the design of your products.

- Describes steps to take in the case that issues arise during the team project.

- Proves that all members understand team goals with each member's signatures.

How will the teamwork agreement be used?

- It is the first tool the team can use if team is not functioning well.

- You will consult the teamwork agreement to resolve issues.

- If an issue cannot be resolved, the agreement will be used in recitation as a guide for discussion with the professor, writing consultant, and teaching assistant.

Although your team may never have trouble during the year, it is better to prepare for the worstcase scenario than to not prepare at all. Hopefully, outlining your feelings about teamwork will make the resolution of your issues easier. You will benefit from dealing with problems early in the semester rather than waiting until it is too late to complete your project.

Please turn in a printout of your signed teamwork agreement during the Milestone 1 recitation to your recitation $T A$.

As you learned in lecture, an EG 1003 team consisting of Prof. Gunter Georgi, Prof. Jack Bringardener, Prof. Chris Leslie, and Head TA Alyssa D'Apice are writing papers and making presentations about teamwork. We are looking for groups who are willing to share their teamwork agreement with us. If you are willing to be included, we will gather your responses anonymously to see what you have included in your agreement. In some cases, we will also quote anonymously from the volunteers' teamwork agreements in our presentations and/or publications. If all members of your team are willing to participate, please email the completed Word file to Alyssa D'Apice < ad'apice@eg.poly.edu>, who will collect your responses and make sure you remain anonymous. In order to protect your privacy, your professor will not know if you have volunteered. Your grade will not be affected if you decide not to participate.

In order to complete the teamwork agreement, please replace the text that says "Type your response here" or "Type name here" on the next page with your responses. 


\section{EG 1003 Teamwork Agreement}

Recitation Section: Type your response here.

Recitation meeting time: Type your response here.

- Communication: How do you prefer to get in contact with each other? What methods of communication will be used?

Type your response here.

- Meetings: How often and when will you meet? What will you do if a team member does not show for a meeting?

Type your response here.

- Differences of opinion: How will you resolve tied votes on decisions? How will you manage disagreements during problem solving?

Type your response here.

- Responsibilities: How will you assign responsibilities? What will you do if a team member fails to complete tasks?

Type your response here.

- Workload: What is a fair workload for each team member?

Type your response here.

Signed

Type name here

Type name here

Type name here (or delete if there are only two members) 